\title{
Monthly average daily global and diffuse solar radiation based on sunshine duration and clearness index for Brasov, Romania
}

\author{
Daniel Tudor Cotfas, ${ }^{1, a)}$ Petru Adrian Cotfas, ${ }^{1}$ Eleni Kaplani, ${ }^{2}$ \\ and Cornel Samoila ${ }^{3}$ \\ ${ }^{1}$ EC Department, Transilvania University of Brasov, B-dul Eroilor 29, Brasov, Romania \\ ${ }^{2}$ Mechanical Engineering Department, T.E.I. of Patras, Meg. Alexandrou 1, Patra, Greece \\ ${ }^{3}$ SM Department, Transilvania University of Brasov, B-dul Eroilor 29, Brasov, Romania
}

(Received 31 March 2013; accepted 15 September 2014; published online 24 September 2014)

\begin{abstract}
The main objective of this study is to develop single location appropriate models for the estimation of the monthly average daily global and diffuse horizontal solar radiation for Brasov, Romania. The study focuses particularly on models based on the sunshine duration and clearness index. The data used for the calibration of the models were collected during a period of $4 \mathrm{yr}$, between November 2008 and October 2012, at the Transilvania University of Brasov. The testing and validation of the models was carried out using data from the online SoDa database for Brasov for the year 2005. Different statistical error tests were applied to evaluate the accuracy of the models. The predicted values are also compared with values from three other known models concerning the global and diffuse solar radiation. A new mixed model was developed for the estimation of monthly average daily global horizontal solar radiation. The data processing was performed by means of a realtime interface developed with LabVIEW graphical programming language. The parameters taken into account were the relative sunshine, the clearness index, the extraterrestrial radiation, the latitude and the longitude. The methodology is simple and effective and may be applied for any region. Its effectiveness was proven through comparison with global models. (C) 2014 AIP Publishing LLC.
\end{abstract}

[http://dx.doi.org/10.1063/1.4896596]

\section{INTRODUCTION}

The amount of solar radiation on the ground, on a surface, through a curved aperture or through windows is a fundamental quantity used in energy balance equations, where it appears in the form of intensity $\left(\mathrm{W} / \mathrm{m}^{2}\right)$, power $(\mathrm{W})$, or energy (Wh) ${ }^{1}$ It is, also, important to provide good estimates and reliable measurements of the solar radiation. The ex ante determination of the useful amount of energy to be delivered in any place through the solar radiation conversion to thermal or electric power is considered as sine qua non for intelligent solar radiation applications. Innovative solar radiation applications in the domestic, industrial, and agricultural sectors are presented and argued in many research works. ${ }^{2-7}$

Many research studies focus on the measurement, monitoring and analysis of horizontal solar radiation at different locations. National and global databases have been developed for this purpose, such as NASA, European GIS databases, etc. ${ }^{8-10}$ The analysis of these data is also useful for the extraction of the values of the most important parameters, or the average values of solar radiation with daily, monthly, or seasonal dependence and variations which might be considered as stochastic. However, in the well-established models for sizing renewable energy systems, mean estimated or average either daily or monthly values of solar radiation are used as input data, see f-chart or $\Phi$-f chart methods. ${ }^{1,11}$ Such values are determined

a)dtcotfas@unitbv.ro 
either by using various models for their prediction or by data bases at national or international level.

The solar energy potential becomes a major consideration in photovoltaic (PV) systems installation, for zero energy or passive solar buildings, agricultural applications like crop drying, green house studies, solar thermal and cooling, climatology, photobiology, etc., ${ }^{2,4,6,12-14}$

The monitoring of the solar radiation is realized by meteorological stations running in various geographical places in all countries which measure mainly global solar radiation and sunshine duration. The diffuse component of the solar radiation is measured by pyranometers with a shadow ring properly attached on to their frame or with shading disc on suntracker, spectroradiometers, etc. The direct component is measured by a pyrheliometer mounted on a sun tracking system.

\section{BRIEF REVIEW OF THE MODELS}

There are several models developed to predict solar radiation profiles on a daily, monthly, and hourly basis. ${ }^{2,12,15-20,26-36,57,58}$ These models are empirical, theoretical, or stochastic, leading to sophisticated models using neural networks and fuzzy logic algorithms. ${ }^{21-25}$ The input data for such models include quantities such as the sunshine duration, the latitude and the longitude, the declination angle, the altitude, the cloudiness, the ambient temperature, the relative humidity, the atmospheric pressure, and precipitate water vapor. ${ }^{2,19,20,26-29,31,35,36}$

The models for the monthly average daily global horizontal solar radiation can be classified in the following categories, see Table $\mathrm{I}^{31}$

The models based on sunshine duration are the most widely studied and used in research studies. These models can be classified in four main groups: ${ }^{19,20}$

- Linear models-based on a modified form of the Angström equation. ${ }^{37}$ The empirical coefficients $\mathrm{a}$ and $\mathrm{b}$ can be obtained using first order regression analysis. Models developed in the literature include annual models, seasonal (separated into two periods October-March and April-September) and monthly models. From a geographical perspective the models can be local, ${ }^{38,39}$ regional, ${ }^{20,31,40}$ or general models. ${ }^{41,42}$

- Polynomial models - based on 2nd or higher order equations; the models developed in the literature also include local, regional, and general models. ${ }^{19,20,31,41,43}$

- Angular models, derived from the Angström equation, have been proposed by many researchers; whereby alongside the monthly relative sunshine duration the models also use input parameters such as the latitude $-\varphi$, the longitude $-\lambda$, and the altitude $-Z$ of the site. ${ }^{19,20,31,44,45}$ In this group of models the linear fitting parameter a is determined as a function of $\varphi, \lambda, \mathrm{Z}^{19,31}$

- Other models - this group comprises the models which cannot be included in the previous categories; these models use other mathematical approximation such as exponential, logarithmic, and power form based equations. ${ }^{19,46-50}$

TABLE I. Model classification.

\begin{tabular}{|c|c|c|}
\hline Type of solar radiation & Model type & Considered parameters of the model \\
\hline \multirow[t]{4}{*}{$\begin{array}{l}\text { Global horizontal } \\
\text { solar radiation }\end{array}$} & Linear or first order & $\begin{array}{c}\text { Sunshine duration, relative humidity, precipitated water vapor, } \\
\text { cloud factor, and atmospheric pressure }\end{array}$ \\
\hline & Polynomial & Sunshine duration and cloud factor \\
\hline & Angular & Altitude, latitude, longitude, declination angle, and elevation \\
\hline & $\begin{array}{l}\text { Other relationships: } \\
\text { logarithmical, exponential, } \\
\text { power forms or other }\end{array}$ & $\begin{array}{l}\text { Sunshine duration, relative humidity, precipitated water vapor, } \\
\text { daily maximum air temperatures, daily minimum air } \\
\text { temperatures, cloud factor, and atmospheric pressure }\end{array}$ \\
\hline \multirow{3}{*}{$\begin{array}{l}\text { Diffuse horizontal } \\
\text { solar radiation }\end{array}$} & Polynomial & sunshine duration \\
\hline & Polynomial & clearness index \\
\hline & Linear & $\begin{array}{c}\text { sunshine duration, clearness index, ambient temperature, } \\
\text { and relative humidity }\end{array}$ \\
\hline
\end{tabular}


The empirical models used to determine the monthly average daily diffuse horizontal radiation can be classified according to the function used for the input parameters. ${ }^{16,19,32,34,51}$

The models can thus be grouped into the following three classes:

- Models based on the clearness index-they can be a linear or other function of the monthly average daily clearness index. ${ }^{16,19,32,34,51,52}$

- Models based on the sunshine duration-they can be a linear function or other function of the monthly average daily sunshine. ${ }^{16,19,32,34}$

- Mixed models based on the mentioned two parameters or on additional parameters such as the ambient temperature, the relative humidity and the monthly average solar altitude at solar noon. ${ }^{16,32,34,53}$

Empirical models that have been proposed in the literature include local models, such as the model developed by El-Sebaii et al. for the city of Jeddah, Saudi Arabia ${ }^{51}$ or by Li et al. for the Guangzhou, China, ${ }^{16}$ regional models, such as the models developed by Ulgen and Hepbasli for three major Turkish cities ${ }^{54}$ or by Haydar et al. for Central Anatolia region of Turkey, ${ }^{55}$ and, finally, general models such as the models developed by Bortolini et al. for the European (EU) geographical area. ${ }^{32}$

\section{METHODOLOGY}

The main objective of this work is to determine the models which provide the best estimates of the monthly average daily global horizontal solar radiation, as well as the monthly average daily diffuse horizontal solar radiation for Brasov, Romania. In order to identify the best models, seven selected models for the estimation of the monthly average daily global horizontal solar radiation, and five models for the monthly average daily diffuse horizontal solar radiation are studied. The selected models are chosen because they are the most widely used by researchers in order to estimate the monthly average daily global and diffuse horizontal solar radiation and they give very good results for different locations. ${ }^{2,19,28,31,32}$ They are briefly presented below.

\section{A. Models used for the monthly average daily global horizontal radiation}

The first model applied is the linear one, proposed by Page, using the modified Angströmtype equation. It is the most widely used method because of its simplicity and the fact that many meteorological stations measure the sunshine duration.

The Angström equation modified by Page is given in the following equation: ${ }^{37,41}$

$$
\frac{H}{H_{o}}=a+b \frac{n}{N}
$$

where $\mathrm{H}$ represents the monthly average daily global radiation, $\mathrm{n}$ is the monthly average daily hours of bright sunshine (h), $\mathrm{H}_{\mathrm{o}}$ represents the monthly average daily extraterrestrial radiation, $\mathrm{N}$ is the monthly average day length ( $\mathrm{h}$ ), and $\mathrm{a}, \mathrm{b}$ are coefficients that have to be empirically determined for the respective area. $\mathrm{N}$ is given in the following equation: ${ }^{1}$

$$
N=2 \omega_{s} / 15
$$

where the sunset hour angle $\omega_{\mathrm{s}}$ is given in the following equation: ${ }^{1}$

$$
\omega_{s}=\cos ^{-1}(-\tan \varphi \tan \delta),
$$

where $\varphi$ represents the latitude and $\delta$ represents the declination.

The monthly average daily extraterrestrial radiation $\mathrm{H}_{\mathrm{o}}$ is given in the following equation: ${ }^{1}$ 


$$
\begin{aligned}
H_{o}= & (0.024 / \pi) I_{s c}[1+0.033 \cos (360 D N / 365)] \\
& \times\left[\cos \varphi \cos \delta \sin \omega_{s}+\left(2 \pi \omega_{s} / 360\right) \sin \varphi \sin \delta\right],
\end{aligned}
$$

where $I_{\mathrm{sc}}$ represents the solar constant with a value of $1366.1 \mathrm{~W} / \mathrm{m}^{2},{ }^{56}$ and $\mathrm{DN}$ is the day number in the year (1-365).

In the linear model of Eq. (1), the coefficients a and b are determined by first order regression analysis of measured data.

From the polynomial group of models, three models are used: second order polynomial proposed by Ogelman et al., given by Eq. (5); third order proposed by Zabara, given by Eq. (6); and fifth order proposed by Bakirci, given by Eq. (7), ${ }^{19,20,31,43,63,64}$

$$
\begin{gathered}
\frac{H}{H_{o}}=a+b \frac{n}{N}+c\left(\frac{n}{N}\right)^{2}, \\
\frac{H}{H_{o}}=a+b \frac{n}{N}+c\left(\frac{n}{N}\right)^{2}+d\left(\frac{n}{N}\right)^{3}, \\
\frac{H}{H_{o}}=a+b \frac{n}{N}+c\left(\frac{n}{N}\right)^{2}+d\left(\frac{n}{N}\right)^{3}+e\left(\frac{n}{N}\right)^{4}+f\left(\frac{n}{N}\right)^{5},
\end{gathered}
$$

where $\mathrm{c}, \mathrm{d}$, e, and $\mathrm{f}$ are the regressions coefficients that have to be empirically determined.

The logarithmic model is the fifth one selected. Newland ${ }^{46}$ and Bakirci ${ }^{48}$ developed such models for the Coastal Region of South China and Turkey. The logarithmic model is given in the following equation:

$$
\frac{H}{H_{o}}=a+b \frac{n}{N}+c \ln \left(\frac{n}{N}\right) .
$$

The sixth model chosen is the exponential model developed by Almorox and Hontoria, given in the following equation: ${ }^{47}$

$$
\frac{H}{H_{o}}=a \exp \left(b \frac{n}{N}\right) .
$$

Kaplanis and Kaplani have proposed a cosine model, given by Eq. (10), ${ }^{57}$ for the prediction of $\mathrm{H}$ as a function of the day number in the year, ${ }^{57,58}$

$$
H=a+b \cos \left(\frac{2 \pi}{365} D N+c\right) .
$$

\section{B. Models used for the monthly average daily diffuse horizontal radiation}

The empirical models used to determine the monthly average daily diffuse horizontal radiation can be classified according to the mathematical function used for the estimation. ${ }^{16,19,51}$

The first empirical model used for comparison was that of Gopinathan ${ }^{53}$ where diffuse horizontal radiation is calculated as function of the clearness index using the following equation:

$$
\frac{H_{d}}{H}=K_{D}=f\left(K_{T}\right),
$$

where $\mathrm{H}_{\mathrm{d}}$ represents the monthly average daily diffuse horizontal radiation, and the function $\mathrm{f}\left(\mathrm{K}_{\mathrm{T}}\right)$ can be a linear function of the monthly average daily clearness index when it varies between 0.3 and 0.7 or a third order polynomial function. ${ }^{31,54,55}$ These correspond to the first 
and second models applied, respectively. $\mathrm{K}_{\mathrm{T}}$ is the clearness index, calculated by the following equation: ${ }^{4}$

$$
K_{T}=\frac{H}{H_{o}} .
$$

The third and fourth empirical models used for the monthly average daily diffuse horizontal radiation in this work take into consideration the sunshine duration, based on the Ibrahim models. ${ }^{65}$ The models is given in the following equation:

$$
\frac{H_{d}}{H}=g\left(\frac{n}{N}\right)
$$

where the function $\mathrm{g}(\mathrm{n} / \mathrm{N})$ can be a linear function, or a second order polynomial function.

The last one is a polynomial approximation developed by Gopinathan ${ }^{53}$ given in the following equation:

$$
\frac{H_{d}}{H}=a+b K_{T}+c \frac{n}{N}
$$

\section{Data collection and LabVIEW application}

Brasov is a city positioned in the central area of Romania. Its geographical coordinates are North latitude $45^{\circ} 39^{\prime} 20^{\prime \prime}$, East longitude $25^{\circ} 36^{\prime} 38^{\prime \prime}$, and $568 \mathrm{~m}$ altitude above sea level.

The data used as inputs for the models are measured by a meteorological station, mounted on the roof of the university building. The pyranometer provides the values of the horizontal global solar radiation, as well as the diffuse horizontal radiation. The data are collected for a period of $4 \mathrm{yr}$, November 2008-October 2012, at 5 min interval.

A complex program was developed in the LabVIEW graphical programming language for the data processing. The data obtained with the pyranometer are saved in "cvs" format and the program permits data conversion and calculation of the monthly average daily extraterrestrial solar radiation, of the monthly average daily global horizontal solar radiation using the selected day or the average for an entire month and the monthly average daily diffuse horizontal solar radiation.

\section{Data filtering procedure}

\begin{tabular}{|c|c|c|}
\hline Step & Data filtering & Description \\
\hline 1 & Available data & Days without $24 \mathrm{~h}$ data availability are not considered in the analysis. \\
\hline 2 & Incidence angle & Data with solar altitude less than $7^{\circ}$ is not considered in the analysis. ${ }^{60}$ \\
\hline 3 & Global radiation values & $\begin{array}{l}\text { Only the data with values in the range } \\
0.03 \mathrm{H}_{\mathrm{o}} \leq \mathrm{H} \leq \mathrm{H}_{\mathrm{o}}(15) \\
\text { is considered. }\end{array}$ \\
\hline 4 & $\begin{array}{l}\text { Available data in function of } \\
\text { clearness index and diffuse fraction }\end{array}$ & $\begin{array}{l}\text { Only the data with values in the range } \\
0<K_{T}<1, \quad 0<K_{D}<1 \text { (16) } \\
\text { is considered }\end{array}$ \\
\hline 5 & Diffuse radiation values & $\begin{array}{l}\text { The data considered are comprised within the } \\
\text { envelope delimitated by the two curves obtained by interpolation, } \\
\text { given in the following equation, } \\
\text { see Figure 1: }\left\{\begin{array}{c}K_{D, l o w}=1.128-1.928 K_{T}+0.691 K_{T}^{2} \\
K_{D, u p}=1.162-0.158 K_{T}-1.29 K_{T}^{2}\end{array}\right.\end{array}$ \\
\hline
\end{tabular}

Data correction procedures are given, presented and explained in Table II.

TABLE II. The procedures of filtering and preprocessing data. 


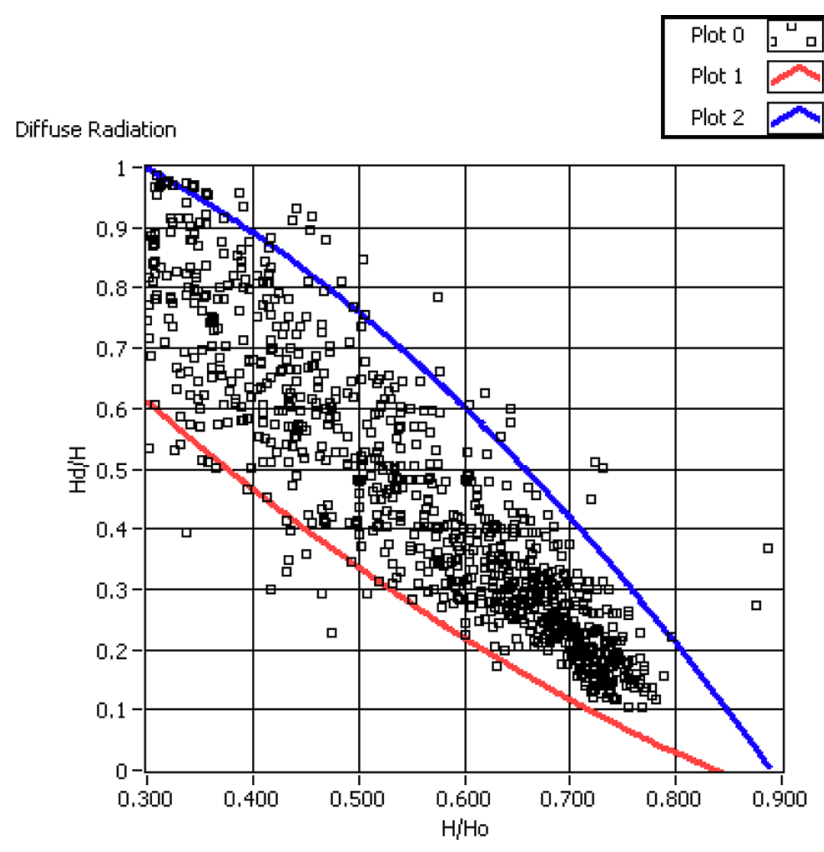

FIG. 1. The scatter envelope.

The concept used in step 5 of Table II to filter the data for the diffuse radiation values is introduced by Claywell et al. ${ }^{60}$ and adopted by Bortolini et al. ${ }^{32}$

\section{E. Statistical tests}

Various statistical error tests were used to evaluate the models. The first statistical error test is the mean absolute error (MAE) given in the following equation:

$$
M A E=\frac{\sum_{i=1}^{n}\left|x_{i c}-x_{i m}\right|}{n},
$$

where $x_{i c}$ represents the calculated values, $x_{i m}$ is the measured values, and $n$ is the total number of measurements. The value for MAE must be very small, a value close to zero is desirable.

Whereas MAE offers information on the long-term performance, the root mean square error (RMSE) test, given in Eq. (19), gives the information on the short-term performance. In order to get accurate estimated values, the RMSE value must be as small as possible,

$$
R M S E=\sqrt{\frac{\sum_{i=1}^{n}\left(x_{i c}-x_{i m}\right)^{2}}{n} .}
$$

If the MBE and RMSE are considered separately the assessment of the best model might be false. The t-statistics is a method to avoid a wrong model selection and is given in the following equation: ${ }^{59}$

$$
t=\sqrt{\frac{(n-1) M B E^{2}}{R M S E^{2}-M B E^{2}}},
$$

where the mean bias error MBE is given in the following equation: 


$$
M B E=\frac{\sum_{i=1}^{n}\left(x_{i c}-x_{i m}\right)}{n} .
$$

The coefficient of determination $\mathrm{R}^{2}$, given by Eq. (22), is a measure of how well the curve fits the data and it value is between 0 and 1 . A value of $R^{2}$ very close to one is desirable,

$$
R^{2}=1-\frac{\sum_{i=1}^{n}\left(x_{i m}-x_{i c}\right)^{2}}{\sum_{i=1}^{n}\left(x_{i m}-\overline{x_{m}}\right)^{2}},
$$

where $\overline{x_{m}}$ is the mean of the measured values.

The relative percentage error calculated for each month is given in Eq. (23). The interval acceptable for the relative percentage is $(-10 \% ; 10 \%)$,

$$
e=\frac{x_{i m}-x_{i c}}{x_{i m}} 100 .
$$

\section{RESULTS AND DISCUSSION}

The empirical coefficients were determined by linear, polynomial, exponential, and logarithmic type fittings according to the various models selected for the monthly average daily global and the monthly average diffuse horizontal solar radiation, using the data measured in the $4 \mathrm{yr}$. The coefficient of determination $\mathrm{R}^{2}$ and RMSE are used to verify the matching between the real data points and the regression data points.

A different set of data obtained from SoDa database ${ }^{62}$ for the same location, Brasov, and year 2005 was used for the validation of the models. Statistical tests MAE, RMSE, t-stat, $\mathrm{R}^{2}$ were utilized for the performance testing.

\section{A. The monthly average daily global horizontal radiation}

The monthly average daily global horizontal solar radiation can be obtained by calculating the average for the entire month or by using for each month, the day when the extraterrestrial solar radiation is equal with the average for the entire month, see Table III. Both methods are used and the results are compared, Figure $2 .^{4}$

There are differences between the daily global horizontal solar radiation for a selected day and the monthly average, see Figure 2. These differences can appear because the selected days can be clear days in winter or cloudy days in summer, so that they significantly differ from the average.

The selected days for every month are used to reduce the calculation time. Taking into consideration these differences, it is better to use the average for the entire month in this study as the software allows the quick calculation of the monthly daily global horizontal solar radiation.

TABLE III. The monthly average daily extraterrestrial and the global horizontal solar radiation for a selected day and average value per month.

\begin{tabular}{lcccccccccccc}
\hline \hline Month & Jan. & Feb. & Mar. & Apr. & May & Jun. & Jul. & Aug. & Sep. & Oct. & Nov. & Dec. \\
\hline Number of selected day & 17 & 16 & 16 & 15 & 15 & 11 & 17 & 16 & 15 & 15 & 14 & 10 \\
$\mathrm{H}_{\mathrm{o}}\left(\mathrm{kW} / \mathrm{m}^{2}\right)$ & 3.30 & 4.83 & 6.90 & 9.18 & 10.87 & 11.59 & 11.23 & 9.82 & 7.71 & 5.43 & 3.66 & 2.90 \\
$\mathrm{H}_{\text {meas } / \text { selected day }}\left(\mathrm{kW} \mathrm{h} / \mathrm{m}^{2}\right)$ & 1.41 & 2.17 & 3.46 & 3.99 & 4.95 & 5.99 & 6.07 & 5.31 & 3.85 & 2.65 & 1.91 & 1.01 \\
$\mathrm{H}_{\text {meas } / \text { average }}\left(\mathrm{kW} \mathrm{h} / \mathrm{m}^{2}\right)$ & 1.23 & 2.13 & 3.42 & 4.16 & 5.06 & 6.17 & 6.01 & 5.49 & 3.99 & 2.47 & 1.75 & 0.99 \\
\hline \hline
\end{tabular}




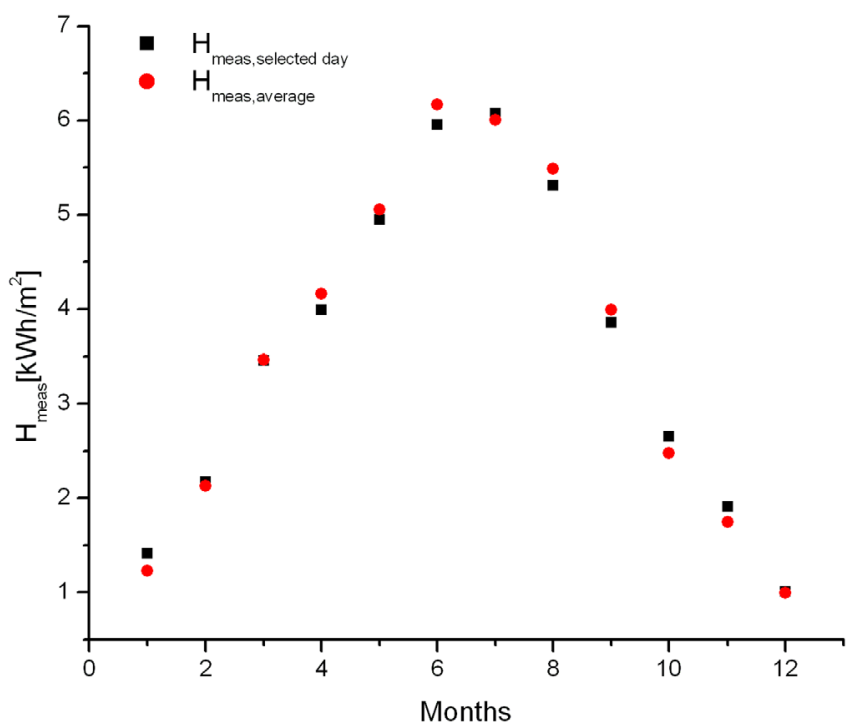

FIG. 2. The comparison between the daily global horizontal solar radiation for the selected day of the month and the monthly average.

The determination of the optimal model for the monthly average daily global horizontal solar radiation for Brasov starts with the simplest one, the linear model. In Figure 3, the dependence between $\mathrm{H} / \mathrm{H}_{\mathrm{o}}$ and $\mathrm{n} / \mathrm{N}$ is represented. The coefficients a and $\mathrm{b}$ are obtained using linear fitting, given in the following equation:

$$
\frac{H}{H_{o}}=0.229+0.53 \frac{n}{N}, \quad R^{2}=0.98 .
$$

The monthly average daily global horizontal solar radiation can be calculated using Eq. (24), by knowing the monthly average daily extraterrestrial radiation and the relative sunshine hours.

The results for the linear, polynomial, exponential, and logarithmic models are presented in Table IV. For the determination of the empirical coefficients of the model proposed by

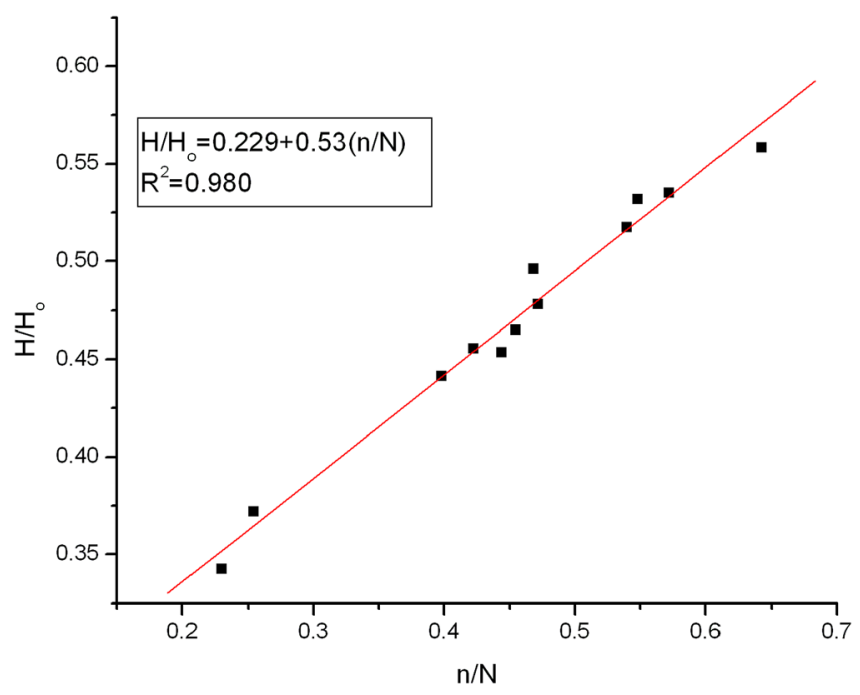

FIG. 3. The linear model developed for Brasov. 
TABLE IV. Empirical coefficients for the selected models of monthly average daily global horizontal solar radiation.

\begin{tabular}{|c|c|c|c|}
\hline Model types & Models obtained for Brasov & RMSE & $\mathrm{R}^{2}$ \\
\hline Linear & $H=H_{o}\left(0.229+0.53 \frac{n}{N}\right)$ & 0.00954 & 0.980 \\
\hline Second order polynomial & $H=H_{o}\left(0.204+0.663 \frac{n}{N}-0.156\left(\frac{n}{N}\right)^{2}\right)$ & 0.00966 & 0.982 \\
\hline Third order polynomial & $H=H_{o}\left(0.342-0.427 \frac{n}{N}+2.485\left(\frac{n}{N}\right)^{2}-2.009\left(\frac{n}{N}\right)^{3}\right)$ & 0.0097 & 0.984 \\
\hline Fifth order polynomial & $H=H_{o}\left(\begin{array}{l}-2.457+32.997 \frac{n}{N}-150.58\left(\frac{n}{N}\right)^{2} \\
+336.64\left(\frac{n}{N}\right)^{3}-363.88\left(\frac{n}{N}\right)^{4}+152.512\left(\frac{n}{N}\right)^{5}\end{array}\right)$ & 0.00922 & 0.989 \\
\hline Exponential & $H=H_{o}\left(0.2776 \exp \left(1.145 \frac{n}{N}\right)\right)$ & 0.00963 & 0.963 \\
\hline Logarithmic & $H=H_{o}\left(0.325+0.41 \frac{n}{N}+0.0479 \ln \left(\frac{n}{N}\right)\right)$ & 0.00973 & 0.982 \\
\hline Kaplanis & $H=3.571+2.534 \cos \left(\frac{2 \pi}{365} D N+3.232\right)$ & 0.2432 & 0.986 \\
\hline
\end{tabular}

Kaplanis, ${ }^{57} \mathrm{DN}$ is considered as the number of the day in the year that corresponds to the selected day, see Table III.

By analyzing the results of Table IV, it can be seen that for all the models chosen the values of the correlation coefficient $\mathrm{R}^{2}$ are higher than $96 \%$. The fifth order polynomial model has the best values for $\mathrm{R}^{2}$, as well as for RMSE.

Validation of the models presented in Table IV is performed using the SoDa database. The results are presented in Table V. The relative percentage error is calculated for each month in order to analyze the matching between the estimated values by modeling and the measured values for the year 2005. The differences for each model between $\mathrm{H}$ measured for the year 2005 and the annual estimated value are also calculated in percentage. The local models are compared with two general ones by Page and Rietveld. ${ }^{41,42}$ The Rietveld model is developed using data collected from 42 stations in different countries and it is given in the following equation:

$$
\frac{H}{H_{o}}=0.18+0.62 \frac{n}{N}
$$

The Page model is developed using data collected from stations placed between the latitudes of $40 \mathrm{~N}-40 \mathrm{~S}$ and it is given in the following equation:

$$
\frac{H}{H_{o}}=0.23+0.48 \frac{n}{N}
$$

TABLE V. Statistical results for selected empirical models with estimated coefficients.

\begin{tabular}{lllllcc}
\hline \hline Model types & MAE & RMSE & t-stat & $\mathrm{R}^{2}$ & $\mathrm{H}_{\text {est }}-\mathrm{H}_{\text {meas }}($ annual $)(\%)$ & $\mathrm{e}(\%)$ \\
\hline Linear & 0.13 & 0.1545 & 5.18 & 0.9986 & -3.55 & $(-5.54 ;-1.58)$ \\
Second order polynomial & 0.114 & 0.138 & 4.98 & 0.9988 & -3.14 & $(-5.59 ;-1.24)$ \\
Third order polynomial & 0.099 & 0.121 & 4.71 & 0.9986 & -2.71 & $(-6.05 ;-0.44)$ \\
Fifth order polynomial & 0.0855 & 0.113 & 3.8 & 0.999 & -2.34 & $(-6.7 ;-0.12)$ \\
Exponential & 0.136 & 0.164 & 4.86 & 0.998 & -3.71 & $(-6.11 ;-1.74)$ \\
Logarithmic & 0.111 & 0.128 & 5.704 & 0.9988 & 2.97 & $(0.37 ; 6.85)$ \\
Kaplanis & 0.188 & 0.265 & 1.463 & 0.98 & -2.93 & $(-16.4 ;-0.44)$ \\
\hline \hline
\end{tabular}


TABLE VI. Statistical results for selected empirical models with universal coefficients.

\begin{tabular}{lcccccc}
\hline \hline Model types & MAE & RMSE & t-stat & $\mathrm{R}^{2}$ & $\mathrm{H}_{\text {est }}-\mathrm{H}_{\text {meas }}$ (annual) $(\%)$ & $\mathrm{e} \mathrm{( \% )}$ \\
\hline Rietveld & 0.178 & 0.194 & 7.506 & 0.998 & -4.84 & $(-12.5 ;-1.9)$ \\
Page & 0.297 & 0.34 & 5.95 & 0.998 & -8.12 & $(-10.54 ;-6.5)$ \\
\hline \hline
\end{tabular}

Taking into account the results of the statistical test, see Table V, the conclusion is that the fifth order polynomial model is the best model for the monthly average daily global horizontal solar radiation for Brasov, with the smallest MAE, RMSE, and t-stat values. A very good matching is obtained between the measured monthly average daily global horizontal solar radiation and the one estimated with the fifth order polynomial model. The value of the correlation coefficient $\mathrm{R}^{2}$ is 0.999 . With respect to the relative percentage $\mathbf{e}$, a much higher dispersion is observed for the Page, Rietveld, and Kaplanis models. The monthly average daily global horizontal solar radiation calculated with Page and Rietveld models lead to underestimated values, see Table VI. The Page and Rietveld are general models. There can still be observed a doubling of the error for the estimation of the annual global solar radiation using the Rietveld model in comparison to the fifth order polynomial model and a four times increase in the case of the Page model. This indicates that local models need to be developed for higher accuracy. Good results are also obtained for the logarithmic model.

Figure 4 renders a comparison between the estimated monthly average daily global horizontal solar radiation and the measured data using SoDa database.

The coefficients of the linear model for two periods of the year were obtained, too. The equations of this model are presented below:

$$
\begin{gathered}
\frac{H}{H_{o}}=0.218+0.547 \frac{n}{N} \quad \text { for April-September }, \\
\frac{H}{H_{o}}=0.219+0.566 \frac{n}{N} \quad \text { for January }- \text { March and October }- \text { December } .
\end{gathered}
$$

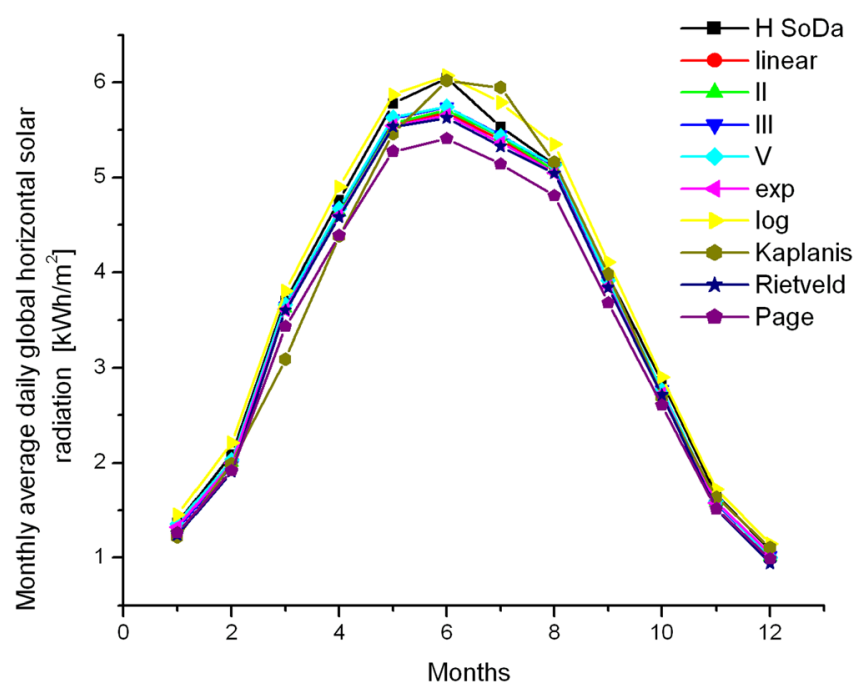

FIG. 4. The comparison between the estimated monthly average daily global horizontal solar radiation and the measured data using SoDa database for 2005. 
The results for the statistical tests are $\mathrm{MAE}=0.128$ and $\mathrm{RMSE}=0.151$. The percentage difference between $\mathrm{H}_{\text {meas }}$ and $\mathrm{H}_{\mathrm{est}}$ is only of $3.14 \%$ by using the linear-two periods model. An improvement is observed in comparison to the linear annual model, see Table $\mathrm{V}$.

The model for every month of the year is also developed. The equations of this model are presented below:

$$
\begin{aligned}
\frac{H}{H_{o}} & =0.218+0.607 \frac{n}{N} \quad \text { for January, } \\
\frac{H}{H_{o}} & =0.270+0.569 \frac{n}{N} \quad \text { for February }, \\
\frac{H}{H_{o}} & =0.241+0.557 \frac{n}{N} \quad \text { for March }, \\
\frac{H}{H_{o}} & =0.170+0.638 \frac{n}{N} \quad \text { for April }, \\
\frac{H}{H_{o}} & =0.198+0.591 \frac{n}{N} \quad \text { for May }, \\
\frac{H}{H_{o}} & =0.217+0.556 \frac{n}{N} \quad \text { for June }, \\
\frac{H}{H_{o}} & =0.228+0.524 \frac{n}{N} \quad \text { for July }, \\
\frac{H}{H_{o}} & =0.191+0.572 \frac{n}{N} \quad \text { for August },
\end{aligned}
$$

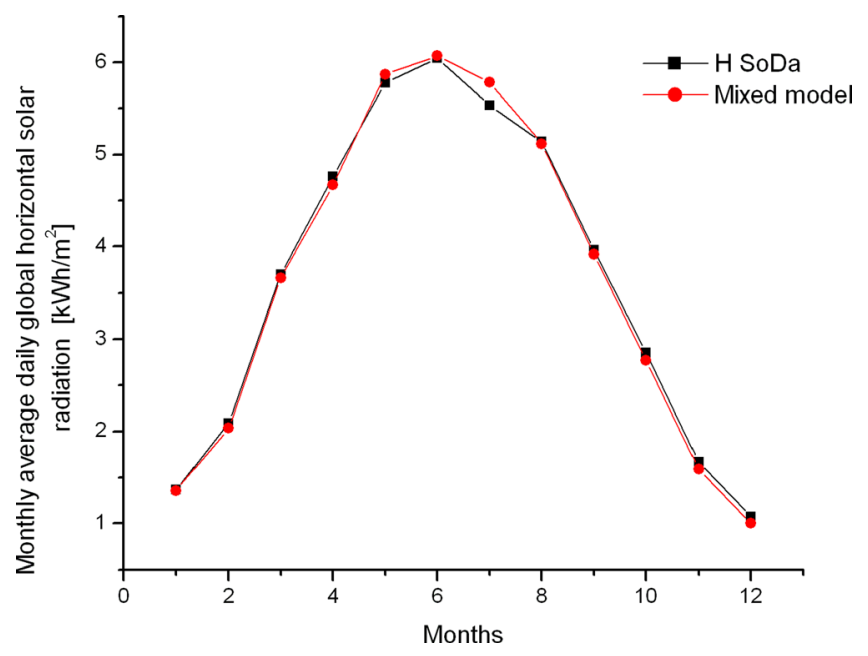

FIG. 5. The comparison between H estimated with mixed model and the H obtained by SoDa for 2005. 
TABLE VII. Empirical coefficients for selected models for the monthly average daily diffuse horizontal solar radiation for Brasov.

\begin{tabular}{lccr}
\hline \hline Model types & Models obtained for Brasov & RMSE & $\mathrm{R}^{2}$ \\
\hline Linear $\left(\mathrm{K}_{\mathrm{T}}\right)$ & $H_{d}=H\left(1.369-1.741 K_{T}\right), 0.3<K_{T}<0.7$ & 0.0416 & 0.89 \\
Third order polynomial $\left(\mathrm{K}_{\mathrm{T}}\right)$ & $H_{d}=H\left(-4.313+35 K_{T}-77.5 K_{T}^{2}+53.86 K_{T}^{3}\right)$ & 0.0038 & 0.926 \\
Linear $(\mathrm{n} / \mathrm{N})$ & $H_{d}=H\left(0.972-0.93 \frac{n}{N}\right)$ & 0.0436 & 0.885 \\
Second order polynomial $(\mathrm{n} / \mathrm{N})$ & $H_{d}=H\left(0.853-0.322 \frac{n}{N}-0.717\left(\frac{n}{N}\right)^{2}\right)$ & 0.043 & 0.894 \\
Mixed model & $H_{d}=H\left(1.234-1.14 K_{T}-0.325 \frac{n}{N}\right)$ & 0.0434 & 0.892 \\
\hline \hline
\end{tabular}

$$
\begin{aligned}
\frac{H}{H_{o}} & =0.216+0.555 \frac{n}{N} \text { for November }, \\
\frac{H}{H_{o}} & =0.204+0.605 \frac{n}{N} \text { for December } .
\end{aligned}
$$

The results for the statistical tests are $\mathrm{MAE}=0.121$ and $\mathrm{RMSE}=0.148$. By using the linear-month model the percentage difference between $\mathrm{H}_{\text {meas }}$ and $\mathrm{H}_{\text {est }}$ is only of $2.91 \%$. An improvement is observed in comparison to the linear annual model, see Table $\mathrm{V}$.

A mixed model is suggested analyzing the results obtained for the $4 \mathrm{yr}$ and considering the best two models of the seven analyzed and it is given in the following equation:

$$
\left\{\begin{array}{c}
H=H_{o}\left(\begin{array}{c}
-2.457+32.997 \frac{n}{N}-150.58\left(\frac{n}{N}\right)^{2}+336.64\left(\frac{n}{N}\right)^{3} \\
-363.88\left(\frac{n}{N}\right)^{4}+152.512\left(\frac{n}{N}\right)^{5}
\end{array}\right) \text { for August-April } \\
H=H_{o}\left(0.325+0.41 \frac{n}{N}+0.0479 \ln \left(\frac{n}{N}\right)\right) \text { for May }- \text { July. }
\end{array}\right.
$$

The mixed model offers highly improved results for the statistical tests: MAE $=0.0727$, $\mathrm{RMSE}=0.095$, t-stat $=0.397$, and $\mathrm{R}^{2}=0.999$. By using this model, the percentage difference between $\mathrm{H}_{\text {est }}$ and $\mathrm{H}_{\text {meas }}$ is only of $0.32 \%$. There is a very good matching between the estimated data with the mixed model and the validation data, and it is illustrated in Figure 5. However, the mixed model overestimates the monthly average daily global horizontal solar radiation for July. The model for monthly average diffuse horizontal solar radiation also overestimates the value for July, as it can be seen below. This month seems to be critical, because other researchers obtained the same results, too. ${ }^{16,36}$

TABLE VIII. Statistical results for selected models.

\begin{tabular}{lcccccc}
\hline \hline Model types & MAE & RMSE & t-stat & $\mathrm{R}^{2}$ & $\mathrm{H}_{\mathrm{d}, \text { meas }}-\mathrm{H}_{\mathrm{d}, \text { est }}(\mathrm{yr})$ & $\mathrm{e}(\%)$ \\
\hline Linear $\left(\mathrm{K}_{\mathrm{T}}\right)$ & 0.051 & 0.067 & 2.01 & 0.996 & $1.98 \%$ & $(-6.05 ; 5.69)$ \\
Third order polynomial $\left(\mathrm{K}_{\mathrm{T}}\right)$ & 0.043 & 0.054 & 0.547 & 0.995 & $0.52 \%$ & $(-3.58 ; 5.91)$ \\
Linear $(\mathrm{n} / \mathrm{N})$ & 0.155 & 0.193 & 4.28 & 0.993 & $8.64 \%$ & $(-0.999 ;-12.71)$ \\
Second order polynomial $(\mathrm{n} / \mathrm{N})$ & 0.168 & 0.212 & 4.24 & 0.992 & $9.49 \%$ & $(-0.31 ; 15.26)$ \\
Mixed $\left(\mathrm{K}_{\mathrm{T}}\right.$ and $\left.\mathrm{n} / \mathrm{N}\right)$ & 0.0853 & 0.114 & 2.92 & 0.996 & $4.29 \%$ & $(-4.2 ; 8.44)$ \\
Multi-location & 0.216 & 0.258 & 4.97 & 0.994 & $12.17 \%$ & $(-0.69 ; 16.46)$ \\
\hline \hline
\end{tabular}




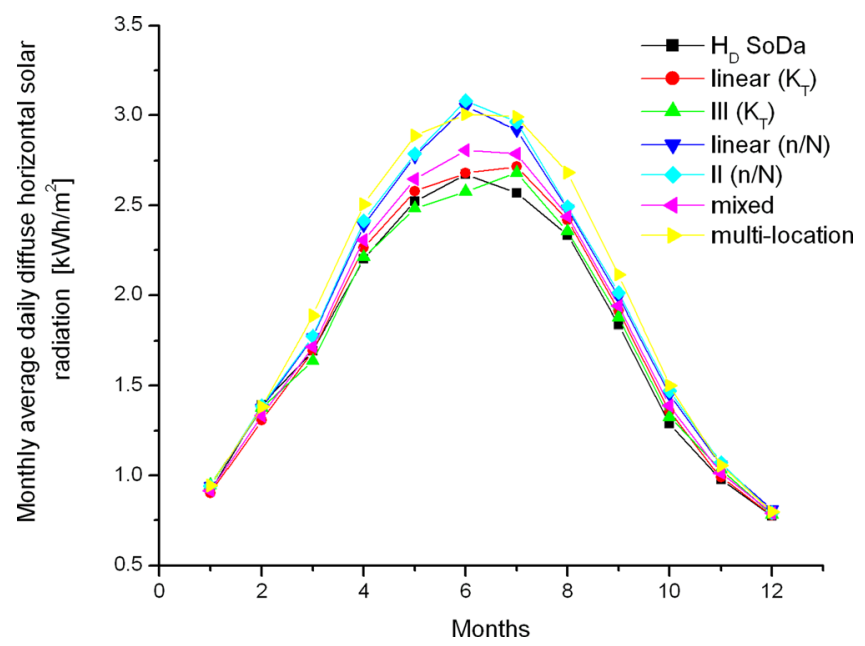

FIG. 6. Comparison between the estimated monthly average diffuse horizontal solar radiation and the $\mathrm{H}_{\mathrm{d}}$ obtained by SoDa for 2005 .

\section{B. The monthly average daily diffuse horizontal radiation}

Using the same methodology as for the monthly average daily global horizontal radiation the following models are developed in order to determine the monthly average daily diffuse horizontal radiation. The results for the linear and polynomial models are presented in Table VII.

By analyzing the results of Table VII, it is observed that the third order polynomial model gives the best results for $\mathrm{R}^{2}$, as well as for RMSE.

The validation tests are repeated for the monthly average daily diffuse horizontal solar radiation and the results are presented in Table VIII. The local models are compared with the multi-location model proposed by Bortolini et al. for Europe, given in the following equation: ${ }^{32}$

$$
H_{d}=H\left(0.9888+0.3950 K_{T}-3.7003 K_{T}^{2}+2.2905 K_{T}^{3}\right) .
$$

Taking into account the statistic test values obtained for different estimated models, it can be observed that the models function of the clearness index gives the best results. The third order polynomial $\left(\mathrm{K}_{\mathrm{T}}\right)$ model confirmed by the performance tests gives values that are close to the ones considered for validation, see Figure 6. Taking into account the relative percentage error e, a greatly higher dispersion is observed for the linear $(\mathrm{n} / \mathrm{N})$, second order polynomial $(\mathrm{n} / \mathrm{N})$, and multi-location models. An error of $12.17 \%$ is observed for the multi-location model, and thus the search for highly accurate local models is required even if a significant model location-dependence is introduced. For Brasov the third order polynomial model $\left(\mathrm{K}_{\mathrm{T}}\right)$ has an error of only $0.52 \%$.

\section{CONCLUSIONS}

Empirical models can be used to estimate the monthly average daily global and diffuse horizontal solar radiation in areas where there are no appropriate measurement devices available.

In this study, several empirical models were fitted with measured data and later compared with a SoDa database in order to assess the validity of the coefficients. These models were applied on the meteorological data base of the Transilvania University of Brasov and verified with data from the SoDa database for 2005 and statistical errors tests.

Seven classical models were developed for the monthly average daily horizontal global radiation, one model for two periods of the year and one for each month, for the city of Brasov. Comparing the data from SoDa database for 2005 with the estimated data using the 
developed models indicates that the most suitable type of model for this type of solar radiation is the fifth order polynomial model with the sunshine duration parameter.

An original model is developed by analyzing the results obtained for the classical models, namely the mixed model, Eq. (28), offering the best matching results between the estimated data and the ones used for validation.

The Rietveld model gives satisfying results to estimate the monthly average daily global horizontal solar radiation for Brasov. The Page model gives underestimated values because the latitude of the town is not in the interval $40 \mathrm{~S}$ and $40 \mathrm{~N}$. Kaplanis model gave underestimated values particularly in March and April and overestimated in July but very close estimates to the measured data during the other months. It is important to note that the Kaplanis model is based only on the day number in the year and this gives an added value, whereas the other models take into account the sunshine duration for the period tested. Kaplanis and Kaplani have also proposed a more complex cosine model which gives better predictions. ${ }^{58}$

For the monthly average daily diffuse horizontal solar radiation five models are developed. The parameters used are the clearness index and the sunshine duration. Using the statistical errors tests to assess the models and the validation data, the third order polynomial model with relative sunshine parameter is the best. The multi-location model proposed for Europe by Bortolini et al. is also tested, and an error of $12.17 \%$ is observed between the estimated data and the ones used for validation.

The data obtained in this study indicated that for a high accuracy both in the case of the monthly average daily global horizontal solar radiation and in the case of the monthly average daily diffuse solar radiation, local models need to be developed. These models can be used successfully for the location for which they are developed.

As shown in this study, the global models for the estimation of the monthly average daily global horizontal solar radiation and diffuse solar radiation gave acceptable estimates. The methodology outlined here using a local model based on regression statistical analysis with solar radiation data available from online databases is applicable to any region and gives closer estimates.

${ }^{1}$ J. A. Duffie and W. A. Beckman, Solar Engineering of Thermal Processes, 3rd ed. (John Wiley \& Sons, Inc., New York, 2006).

${ }^{2}$ K. Ulgen and A. Hepbasli, “Solar radiation models. Part 1: A review," Energy Sources 26, 507-520 (2004).

${ }^{3}$ B. Sørensen, Renewable Energy, 3rd ed. (Elsevier, Inc., 2004).

${ }^{4}$ T. Muneer, Solar Radiation and Daylight Models (Elsevier, Inc., 2004).

${ }^{5}$ D. H. W. Li and J. C. Lam, "Solar heat gain factors and the implications for building designs in subtropical regions," Energy Build. 32, 47-55 (2000).

${ }^{6} \mathrm{R}$. Kumar and L. Umanand, "Estimation of global radiation using clearness index model for sizing photovoltaic system," Renewable Energy 30, 2221-2233 (2005).

${ }^{7}$ Z. Lu, R. H. Piedrahita, and C. D. S. Neto, "Generation of daily and hourly solar radiation values for modeling water quality in aquaculture ponds," Trans. ASAE 41, 1853-1859 (1998).

${ }^{8}$ See http://eosweb.larc.nasa.gov/sse for solar radiation databases.

${ }^{9}$ See http://re.jrc.ec.europa.eu/pvgis/imaps/index.htm for solar radiation databases.

${ }^{10}$ See http://meteonorm.com solar radiation databases.

${ }^{11}$ K. A. Joudi and Q. J. Abdul-Ghafour, "Development of design charts for solar cooling systems. Part I: Computer simulation for a solar cooling system and development of solar cooling design charts," Energy Convers. Manage. 44, 313-39 (2003).

${ }^{12}$ L. T. Wong and W. K. Chow, "Solar radiation model," Appl. Energy 69, 191-224 (2001).

${ }^{13}$ J. H. S. Trujillo, "Solar performance and shadow behaviour in buildings-Case study with computer modelling of a building in Loranca," Spain, Build. Environ. 33, 117-130 (1998).

${ }^{14}$ T. J. Cartwright, "Here comes the Sun: Solar energy from a flat-plate collector," in Modeling the World in a SpreadsheetEnvironmental Simulation on a Microcomputer (The Johns Hopkins University Press, 1993), pp. 121-144.

${ }^{15} \mathrm{C}$. Gueymard, "Critical analysis and performance assessment of clear-sky solar-irradiance models using theoretical and measured data," Sol. Energy 51, 121-138 (1993).

${ }^{16} \mathrm{H}$. Li, W. Ma, X. Wang, and Y. Lian, "Estimating monthly average daily diffuse solar radiation with multiple predictors: a case study," Renewable Energy 36, 1944-1948 (2011).

${ }^{17}$ M. J. Ahmad and G. N. Tiwari, "Solar radiation models-A review," Int. J. Energy Res. 35, 271-290 (2011)

${ }^{18}$ M. J. Ahmad and G. N. Tiwari, "Evaluation and comparison of hourly solar radiation models," Int. J. Energy Res. 33, 538-552 (2009).

${ }^{19} \mathrm{~K}$. Bakirci, "Models of solar radiation with hours of bright sunshine: A review," Renewable Sustainable Energy Rev. 13, 2580-2588 (2009).

${ }^{20} \mathrm{~K}$. Ulgen and A. Hepbasli, "Solar radiation models. Part 2: Comparison and developing new models," Energy Sources 26, 521-530 (2004). 
${ }^{21}$ S. Kalogirou, Artificial Intelligence in Energy and Renewable Energy Systems (Nova Science Publisher, Inc., 2007).

${ }^{22}$ Z. Sen, "Fuzzy algorithm for estimation of solar irradiation from sunshine duration," Solar Energy 63, 39-49 (1998).

${ }^{23}$ A. Sözen, E. Arcaklioğlu, M. Özalp, and E. G. Kanit, "Use of artificial neural networks for mapping of solar potential in Turkey," Appl. Energy 77, 273-286 (2004).

${ }^{24}$ R. K. Tomar, N. D. Kaushika, and S. C. Kaushik, "Artificial neural network based computational model for the prediction of direct solar radiation in Indian zone,” J. Renewable Sustainable Energy 4, 063146 (2012).

${ }^{25}$ A. A. Pérez Ponce, J. A. Lazzús, and L. Palma-Chilla, "Hybrid neural network-particle swarm method to predict global radiation over the Norte Chico (Chile)," J. Renewable Sustainable Energy 4, 023108 (2012).

${ }^{26}$ I. Korachagaon and V. N. Bapa, "Predicting global solar radiation for South America," J. Renewable Sustainable Energy 4, 043101 (2012).

${ }^{27}$ A. H. Maghrabi, "Parameterization of a simple model to estimate monthly global solar radiation based on meteorological variables, and evaluation of existing solar radiation models for Tabouk, Saudi Arabia," Energy Convers. Manage. 50, 2754-2760 (2009).

${ }^{28} \mathrm{~K}$. Ulgen and A. Hepbasli, "Comparison of solar radiation correlations for Izmir, Turkey," Int. J. Energy Res. 26, 413-430 (2002).

${ }^{29}$ D. B. Ampratwum and A. S. S. Dorvlo, "Estimation of solar radiation from the number of sunshine hours," Appl. Energy 63, 161-167 (1999).

${ }^{30}$ W. B. Wan Nik, M. Z. Ibrahim, K. B. Samo, and A. M. Muzathik, "Monthly mean hourly global solar radiation estimation," Sol. Energy 86, 379-387 (2012).

${ }^{31}$ F. Besharat, A. A. Dehghan, and A. R. Faghih, "Empirical models for estimating global solar radiation: A review and case study," Renewable Sustainable Energy Rev. 21, 798-621 (2013).

${ }^{32}$ M. Bortolini, M. Gamberi, A. Graziani, R. Manzini, and C. Mora, "Multi-location model for the estimation of the horizontal daily diffuse fraction of solar radiation in Europe," Energy Convers. Manage. 67, 208-216 (2013).

${ }^{33}$ J. L. Torres, M. De Blas, A. García, and A. de Francisco, "Comparative study of various models in estimating hourly diffuse solar irradiance," Renewable Energy 35, 1325-1332 (2010).

${ }^{34}$ Y. Jiang, "Correlation for diffuse radiation from global solar radiation and sunshine data at Beijing, China," J. Energy Eng. 135, 107-111 (2009).

${ }^{35}$ M. F. Li, H. B. Liu, P. T. Guo, and W. Wu, "Estimation of daily solar radiation from routinely observed meteorological data in Chongqing, China,” Energy Convers. Manage. 51, 2575-2579 (2010).

${ }^{36}$ M. S. Adaramola, "Estimating global solar radiation using common meteorological data in Akure, Nigeria," Renewable Energy 47, 38-44 (2012).

${ }^{37}$ A. Angström, "Solar and terrestrial radiation," Q. J. R. Meteorol. Soc. 50, 121-125 (1924).

${ }^{38} \mathrm{~F}$. Ahmad and I. Ulfat, "Empirical models for the correlation of monthly average daily global solar radiation with hours of sunshine on a horizontal surface at Karachi, Pakistan,” Turk. J. Phys. 28, 301-307 (2004).

${ }^{39}$ A. A. El-Sebaii, A. A. Al-Ghamdi, F. S. Al-Hazmi, and A. Faidah, "Estimation of global solar radiation on horizontal surfaces in Jeddah, Saudi Arabia," Energy Policy 37, 3645-3649 (2009).

${ }^{40}$ A. Soler, "Statistical comparison for 77 European stations of 7 sunshine-based models," Sol. Energy 45, 365-370 (1990).

${ }^{41}$ J. K. Page, "The estimation of monthly mean values of daily total short wave radiation on vertical and inclined surface from sunshine records for latitudes 40N-40S," Proc. U. N. Conf. New Sources of Energy 4(598), 378-390 (1961).

${ }^{42}$ A. Soler, "Monthly specific Rietveld's correlations," Sol. Wind Technol. 7, 305-308 (1990).

${ }^{43}$ K. Bakirci, "Correlations for estimation of solar radiation on horizontal surface," J. Energy Eng. 134, 130-134 (2008).

${ }^{44}$ A. A. Elagib and M. G. Mansell, "New approaches for estimating global solar radiation across Sudan," Energy Convers. Manage. 41, 419-434 (2000).

${ }^{45}$ C. Rensheng, L. Shihua, K. Ersi, Y. Jianping, and J. Xibin, "Estimating daily global radiation using two types of revised models in China," Energy Convers. Manage. 47, 865-878 (2006).

${ }^{46}$ F. J. Newland, "A study of solar radiation models for the Coastal Region of South China," Sol. Energy 43, 227-235 (1989).

${ }^{47}$ J. Almorox and C. Hontoria, "Global solar radiation estimation using sunshine duration in Spain," Energy Convers. Manage. 45, 1529-1535 (2004).

${ }^{48}$ K. Bakirci, "Correlations for estimation of daily global solar radiation with hours of bright sunshine in Turkey," Energy 34, 485-501 (2009).

${ }^{49}$ A. M. Muzathik, M. Z. Ibrahim, K. B. Samo, and W. B. Wan Nik, "Estimation of global solar irradiation on horizontal and inclined surfaces based on the horizontal measurements," Energy 36, 812-818 (2011).

${ }^{50}$ A. K. Katiyar and C. K. Pandey, "A review of solar radiation models-Part I," J. Renewable Energy 2013, 168048.

${ }^{51}$ A. A. El-Sebaii, F. S. Al-Hazmi, A. A. Al-Ghamdi, and S. J. Yaghmour, "Global, direct and diffuse solar radiation on horizontal and tilted surfaces in Jeddah, Saudi Arabia," Appl. Energy 87, 568-576 (2010).

${ }^{52}$ J. Boland, B. Ridley, and B. Brown, "Models of diffuse solar radiation," Renewable Energy 33, 575-584 (2008).

${ }^{53}$ K. K. Gopinathan, "Computing the monthly mean daily diffuse radiation from clearness index and percent possible sunshine," Sol. Energy 41, 379-385 (1988).

${ }^{54}$ K. Ulgen and A. Hepbasli, "Diffuse solar radiation estimation models for Turkey's big cities," Energy Convers. Manage. 50, 149-156 (2009).

${ }^{55}$ A. Haydar, O. Balli, and A. Hepbasli, "Estimating the horizontal diffuse solar radiation over the Central Anatolia region of Turkey," Energy Convers. Manage. 47, 2240-2249 (2006).

${ }^{56}$ C. A. Gueymard, "The sun's total and spectral irradiance for solar energy applications and solar radiation models," Sol. Energy 76, 423-453 (2004).

${ }^{57}$ S. N. Kaplanis, "New methodologies to estimate the hourly global solar radiation: Comparisons with existing models," Renewable Energy 31, 781-790 (2006).

${ }^{58}$ S. Kaplanis and E. Kaplani, "A model to predict expected mean and stochastic hourly global solar radiation I(h;nj) values," Renewable Energy 32, 1414-1425 (2007).

${ }^{59}$ R. J. Stone, "Improved statistical procedure for the evaluation of solar radiation estimation models," Sol. Energy 51, 289-291 (1993). 
${ }^{60}$ S. Younes, R. Claywell, and T. Muneer, "Quality control of solar radiation data: present status and proposed new approaches," Energy 30, 1533-1549 (2005).

${ }^{61}$ I. Moradi, "Quality control of global solar radiation using sunshine duration hours," Energy 34, 1-6 (2009)

${ }^{62}$ See http://www.soda-is.com/eng/index.html for solar radiation data—SoDa Database.

${ }^{63} \mathrm{H}$. Ogelman, A. Ecevit, and E. Tasdemiroglu, "A new method for estimating solar radiation from bright sunshine data," Sol. Energy 33, 619-625 (1984).

${ }^{64}$ K. Zabara, "Estimation of the global solar radiation in Greece," Sol. Wind Technol. 3(4), 267-272 (1986).

${ }^{65}$ S. M. A. Ibrahim, "Diffuse solar radiation in Cairo, Egypt," Energy Convers. Manage. 25(1), 69-72 (1985). 
Journal of Renewable \& Sustainable Energy is copyrighted by the American Institute of Physics (AIP). Redistribution of journal material is subject to the AIP online journal license and/or AIP copyright. For more information, see

http://jrse.aip.org/about/rights_and_permissions. 